\title{
Biomedical research at the Population Council
}

Population Council

Follow this and additional works at: https://knowledgecommons.popcouncil.org/

series_newsletters_momentum

How does access to this work benefit you? Let us know!

\section{Recommended Citation}

"Biomedical research at the Population Council," Momentum newsletter. New York: Population Council, 2015. 


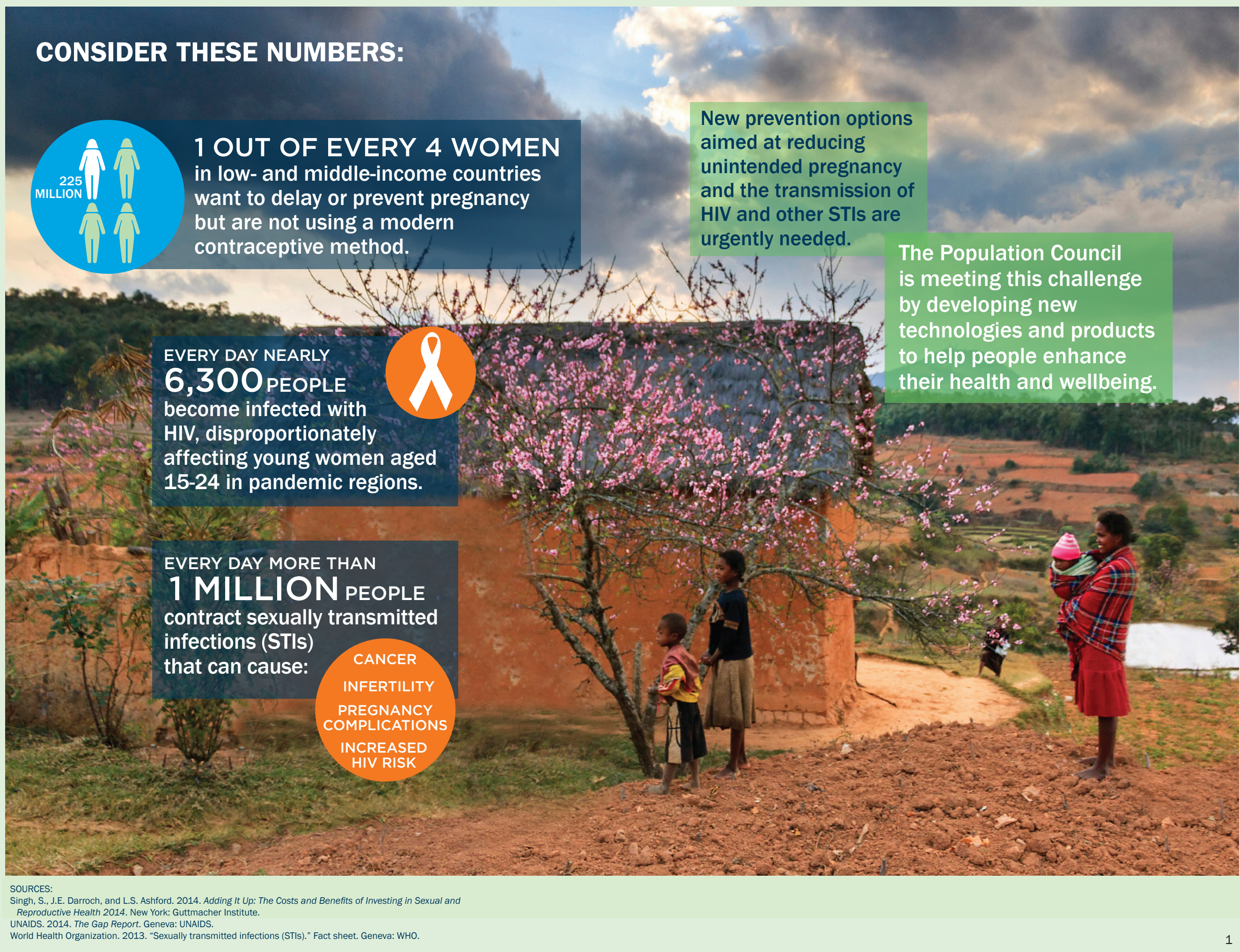




\section{RESEARCH AND DEVELOPMENT TO IMPROVE REPRODUCTIVE HEALTH}

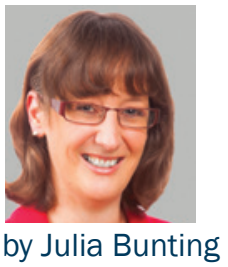

Since it was founded in 1956, the Population Council's Center for Biomedical Research (CBR) has specialized in researching and developing drugs, technologies, and products that enable women, men, and young people to protect and enhance their reproductive health and wellbeing. Hundreds of millions of women have used a family planning method developed by the Council, including the Copper T IUD, the Mirena ${ }^{\circledR}$ intrauterine system, the implants Norplant ${ }^{\circledR}$ and Jadelle ${ }^{\circledR}$, and the progesterone contraceptive vaginal ring for breastfeeding women. Since the beginning of the HIV epidemic in the 1980s, the Council has also conducted research to identify new, user-controlled methods to prevent HIV infection.

Today, Council scientists at CBR are researching new technologies-rings, gels, and other systems-to provide even greater contraceptive choice as well as protection from HIV and other sexually transmitted infections. My colleagues identify leads for new products, develop the most promising ideas through years of research, work with regulatory authorities to secure approval for these technologies, and collaborate with pharmaceutical companies, governments, and a host of other partners to bring these products to market. This work is literally improving the lives of millions of people around the world today and the benefits of these investments will continue for generations to come.

In this issue of Momentum you will read about the Council's rich and distinguished history of biomedical research and the significant impact of this work on women's reproductive health (page 4). You will see how the Council continues to be at the cutting edge of developing new contraceptive vaginal rings (page 10), as well as the Council's work to expand access to long-acting reversible contraception (page 12). Council researchers are also exploring innovative contraceptive methods for men (page 6), and multipurpose prevention technologies to protect against various sexual and reproductive health risks (page 8).

You will meet Council scientist José Fernández Romero, who is identifying new ways to prevent HIV and other sexually transmitted infections (page 14), and Barbara Ebert, a decades-long supporter of the Council's work to develop new contraceptive methods (page 15).

I am deeply honored to have joined the Population Council, and I am committed to building on our strong legacy and investing in a bright future of biomedical research.

\section{Together we will continue}

to provide women, men, and young people around the world with new products to safeguard their wellbeing and help them live more productive, healthier lives.

Thank you for your support. 


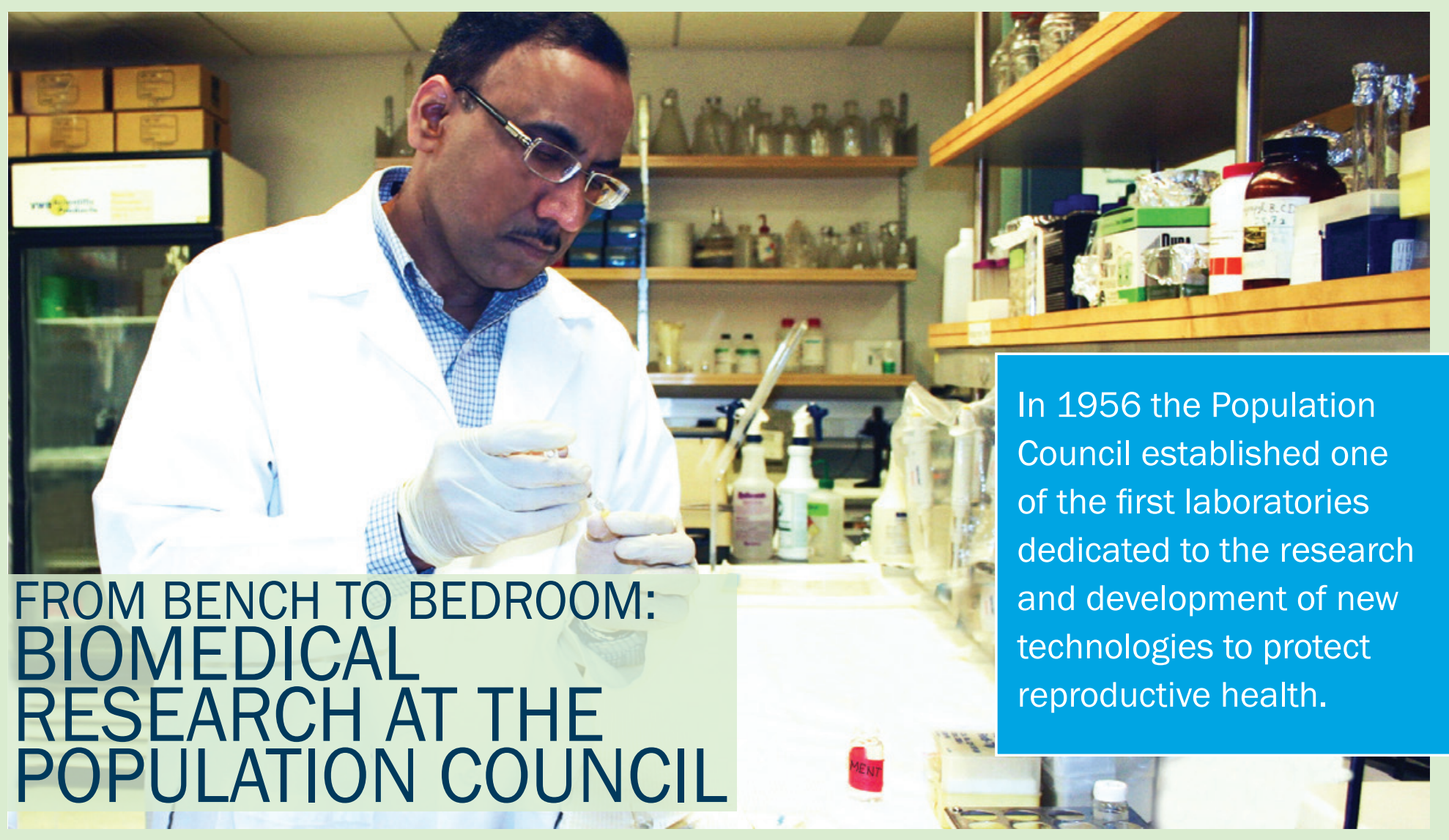

The Population Council's Center for Biomedical Research (CBR) is at the vanguard of global research and development (R\&D) efforts focusing on contraception, preventing HIV and other sexually transmitted infections (STIs), and identifying novel approaches to improve health.

The Council helped establish the field of long-acting, reversible contraception (LARC) in the early 1960s, working with international partners to develop the " $\mathrm{T}$ " shape of the modern intrauterine device (IUD) and identifying the contraceptive action of copper. The Council's first Copper T IUD was approved by the US Food and
Drug Administration in 1976; in 1984, the FDA approved the Council's 10-year Copper T380 IUD (ParaGard ${ }^{\circledR}$ )-the most popular nonsurgical contraceptive method used worldwide.

Contraceptive implant technology was another breakthrough spearheaded by the Council in the mid-1960s, culminating in the five-year hormonal implant systems known as Norplant ${ }^{\circledR}$ and Jadelle ${ }^{\circledR}$ (approved by the FDA in 1990 and 1996, respectively). Other LARC methods pioneered by Council five-year Mirena ${ }^{\circledR}$ intrauterine system and a three-month progesterone vagiresearchers and partners include the be effective for HIV prevention, R\&D for microbicides and multipurpose preven- tion technologies (MPTs) continues to evolve. The Council is now advancing promising options for user-controlled prevention of HIV and other STIs, as well as MPTs that provide contraception in addition to HIV and/or STI prevention.

Today CBR is a vibrant hub of R\&D on the campus of Rockefeller University in New York City-and the need for new sexual and reproductive health technologies is just as urgent now as it was nearly 60 years ago. The R\&D process is long and complex, particularly when products are being developed for lowresource settings where diverse needs and challenges must be addressed. Council discoveries have led to identifying potential added health benefits of several products in the pipeline, such as protective effects of novel contraceptive hormones on breast and prostate health. Basic science research at CBR has also opened doors to exploring new treatments for chronic conditions such as uterine fibroids and multiple sclerosis.

The Council proudly invests in the full R\&D lifecycle, taking a "bench to bedroom" approach that focuses on end-users from the start and works with partners to identify and fill product niches that are otherwise not profitable for traditional biotechnology or pharmaceutical companies. The Council's R\&D efforts lead to safe and effective products that are acceptable, accessible, and designed to meet people's varying sexual and reproductive health needs at different points in their lives. 


\section{MALE CONTRACEPTION IN DISCOVERY}

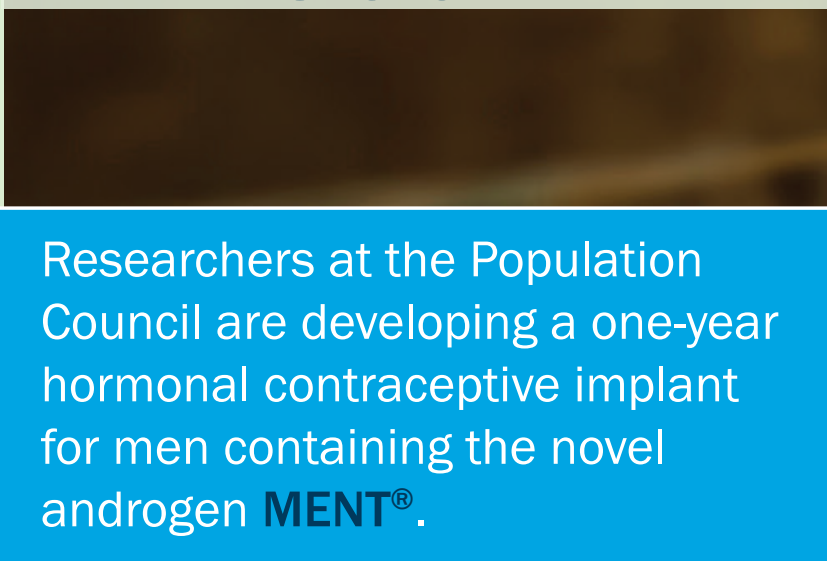

\section{THE PROBLEM There is a recog-} nized need for long-acting reversible contraception (LARC) for men, but as yet there are no available methods. Studies suggest that women and men would enthusiastically welcome additional male contraceptive choices, which would enable men to better share the responsibility, risks, and costs of family planning. The male reproductive system offers several potential targets for both hormonal and non-hormonal contraception; however, many challenges exist including the necessity of stopping daily production of millions of sperm. A safe, effective, acceptable male LARC requires an approach that will reduce sperm count without daily use.
THE PROGRESS Through the development of MENT ${ }^{\circledR}$ from a synthetic steroid that resembles testosterone, researchers have discovered that administering an androgen (a male sex hormone) in combination with a synthetic progestin (another hormone) can reduce sperm count without impairing a man's sex drive. The Council tested this approach in early clinical studies, which showed promising results by inhibiting sperm production using four MENT implants in healthy men. The next step will be a randomized study to evaluate the safety and efficacy of MENT, either alone or in conjunction with the injectable progestin known as DMPA (Depo-Provera ${ }^{\circledR}$ ), to determine whether the combination of MENT and a synthetic progestin reduces sperm count more quickly and effectively.

THE IMPACT New, effective options for male contraception would expand the mix of available family planning methods. Among men who reported being interested in using male contraception, 30\% said they would prefer implants. Unlike testosterone, MENT does not enlarge the prostate; and because of its high potency, a low daily dose can be administered, making delivery through an implant system preferable for long-term use. Discovery of the second active component will take the MENT implant technology one step closer to becoming a viable LARC option for men.
PARTNERS Bayer Schering HealthCare; Christina Wang (David Geffen School of Medicine, University of California, Los Angeles); Crystal Pharma; David T. Baird (U.K. Medical Research Council [MRC] Centre for Reproductive Health at the University of Edinburgh [formerly the MRC Reproductive Biology Unit]); Eberhard Nieschlag (Center for Reproductive Medicine and Andrology of the University Hospital of Munster, Germany); Horacio Croxatto (Instituto Chileno de

Medicina Reproductiva [ICMER], Santiago, Chile); Richard Anderson (U.K. MRC Centre for Reproductive Health at the University of Edinburgh)

DONORS U.S. National Institutes of Health Eunice Kennedy Shriver National Institute of Child Health and Human Development; The George J. Hecht Fund; The Lita Annenberg Hazen Foundation; The William and Flora Hewlett Foundation; Population Council 


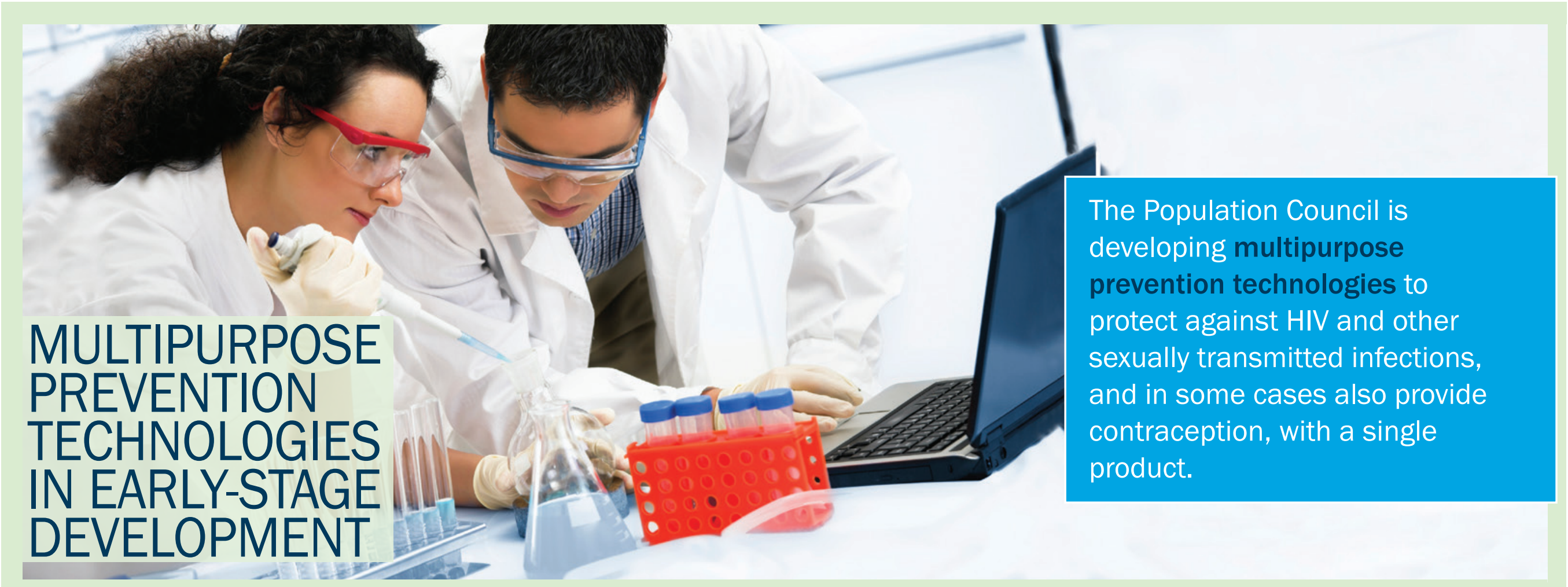

THE PROBLEM Male and female condoms are currently the only available products designed to provide concurrent protection against pregnancy and sexually transmitted infections (STIs), including HIV. Condoms are effective when used correctly, but there are many barriers to use and they are not practical for women and couples who want to have children. New products are needed to address the needs of women and men at risk for STIs, HIV, and unintended pregnancy.

\section{THE PROGRESS The Population} Council has long-acting vaginal rings and on-demand multipurpose prevention technologies (MPTs) in varying stages of development. Several candidates contain a combination of MIV-150 (M), an antiretroviral (ARV) drug that prevents HIV from infecting target cells; zinc acetate (Z), an antiviral agent with activity against HIV and genital herpes simplex virus (HSV-2); and carrageenan (C), a seaweedderived compound active against human papillomavirus (HPV). The MZC vaginal ring is designed to prevent HIV and other STIs for 90 days; the MZCL ring offers these same potential benefits and adds the contraceptive levonorgestrel $(\mathrm{L})$ to prevent pregnancy. The Council has produced and tested prototype rings in preclinical and animal studies with promising results and recently completed a Phase I clinical safety trial of an MZC vaginal gel. A nonARV ZC gel has also been found to be safe and active against HIV, HPV, and HSV-2 in preclinical studies. Products are also being developed with griffithsin, a naturally occurring algae protein shown to be safe and highly effective against HIV in the lab and against HSV-2 and HPV in preclinical studies. A griffithsin gel is being tested to help develop a sustained-release vaginal ring and a nanofiber delivery system (a film-like formulation) to provide protection at the time of sex. The first human studies of griffithsin vaginal gel are expected to begin in 2016.

THE IMPACT If proven effective, these MPTs could contribute substantially to global health. MZC-based products could increase protection against HIV and HSV-2 at lower doses, which in turn could improve product safety, decrease chances of drug resistance, and reduce costs. Non-ARV-based MPT products (e.g., those containing ZC or griffithsin) could help to reduce the emergence of drug-resistant HIV types, eliminate the need for HIV screening prior to use, and potentially be provided over-the-counter. Council researchers are working with academic, nonprofit, and industry experts to advance promising candidates through the pipeline and to identify strategies for introduction and scale-up to ensure that MPTs, once available, are accessible to those most in need.

COLLABORATORS Duke University; Fraunhofer Center for Molecular Biotechnology; ProMed Pharma; Tulane National Primate Research Center; University of Alabama at Birmingham; University of Washington

DONORS U.S. National Institutes of Health National Institute of Allergy and Infectious Diseases; U.S. President's Emergency Plan for AIDS Relief (PEPFAR); United States Agency for International Development (USAID); Sweden Ministry for Foreign Affairs 


\section{CONTRACEPTIVE VAGINAL RINGS IN LATE-STAGE DEVELOPMENT}

The Population Council has developed two innovative contraceptive vaginal rings to meet women's varying family planning needs: a three-month ring that contains progesterone for use by breastfeeding women, and an investigational one-year ring that can prevent pregnancy for a full year.

\section{THE PROBLEM Women in low-} resource settings face unique barriers to obtaining effective contraception, including limited access to different options and a lack of trained health professionals to provide services or counseling. In addition, although exclusive breastfeeding may prevent pregnancy for the first six months after childbirth, return to fertility can occur sooner than anticipated, leaving women at risk for unintended pregnancy, unsafe abortion, and poor health outcomes. There is an urgent need for convenient new contraceptive methods that are safe, effective, easy to use, and under a woman's control.

THE PROGRESS The Council's three-month progesterone vaginal ring (PVR) can be used safely by breastfeed- ing women to help space pregnancies. It does not affect lactation and does not require insertion by a healthcare provider. Each PVR can be used continuously for three months, and rings can be used successively for up to a year. Fertility returns shortly after removal. The ring has been available in Latin America since 1998 under the brand name Progering ${ }^{\circledR}$. The Council is working to introduce the PVR in more countries where prolonged lactation is vital for infant health-and where access to highly effective contraceptives is limited.

The one-year ring prevents pregnancy by releasing a low dose of ethinyl estradiol (EE), an approved, marketed hormonal product, and Nestorone ${ }^{\circledast}$ (NES), an investigational progestin that has been shown to be highly effective in preventing ovulation. The NES/EE ring is inserted by the woman, left in place for 21 days, and removed for 7 days. One ring can be used for up to 13 cycles (one year), and fertility returns after discontinuing use. The Council is preparing to submit a New Drug Application to the US Food and Drug Administration and will seek to introduce the one-year $\mathrm{NES} / \mathrm{EE}$ ring in various settings, including in low- and middle-income countries.

THE IMPACT The PVR is currently available to women in Bolivia, Chile, CoIombia, Dominican Republic, Ecuador, Guatemala, Honduras, and Peru, and the market is now expanding to include regulatory applications in Brazil and Mexico. The Council is also working toward product introduction in India, Kenya, Nigeria, and
Senegal, with the goal of expanding to other countries. The Council's one-year NES/EE ring, if approved by the FDA, would be a unique long-acting reversible contraceptive that is effective for 13 cycles, is under the woman's control, and does not require insertion or removal by a trained healthcare provider.

PARTNERS Bill \& Melinda Gates Institute for Population and Reproductive Health; Grünenthal (formerly Andromaco); International Committee for Contraception Research; Ministries of Health of India, Kenya, Nigeria, and Senegal; QPharma; WomenCare Global; World Health Organization

DONORS Barrus Foundation; Bill \& Melinda Gates Foundation; U.S. Agency for International Development; U.S. National Institutes of Health Eunice Kennedy Shriver National Institute of Child Health and Human Development Contraceptive Clinical Trials Network 


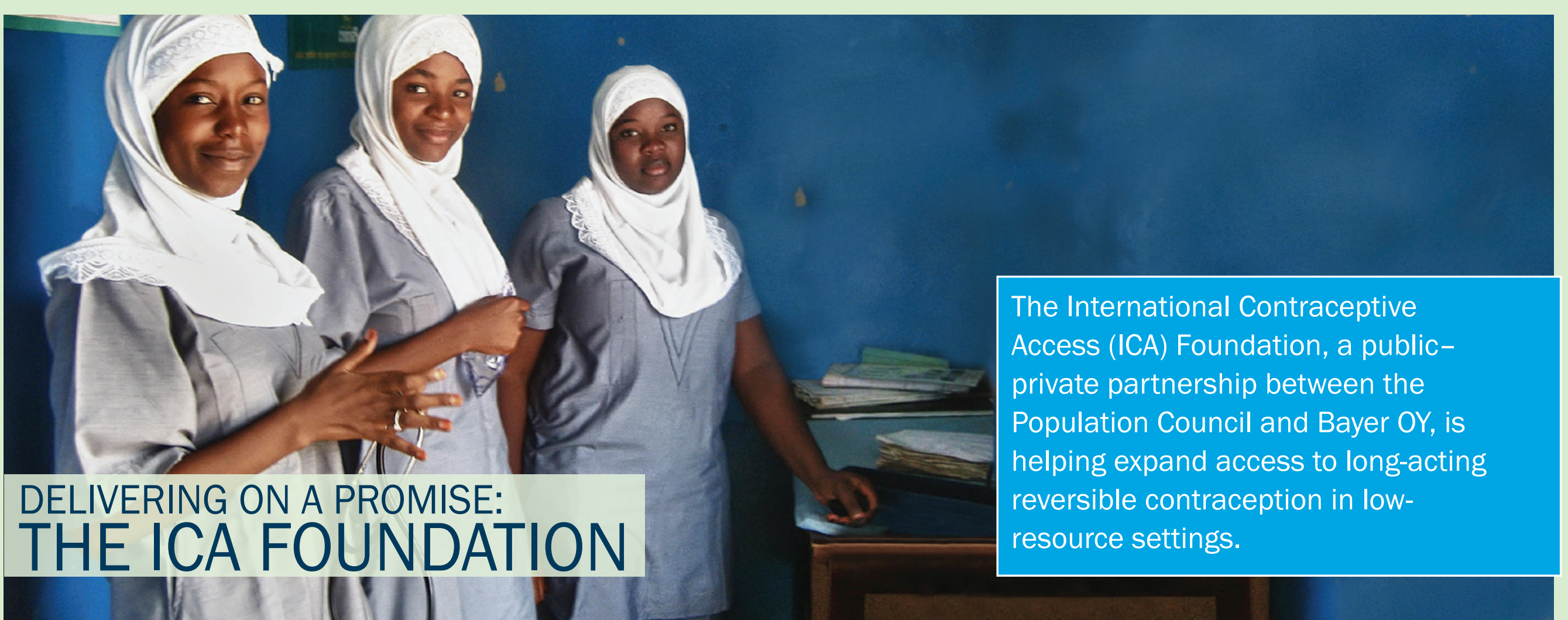

THE PROBLEM The levonorgesterel intrauterine system (LNG IUS) provides up to five years of safe, effective, and continuous contraception. Developed by the Population Council and Finlandbased Bayer OY, the LNG IUS is distributed by Bayer HealthCare Pharmaceuticals in the private market under the trade name Mirena ${ }^{\circledR}$ in more than 120 countries. In low-resource settings, the LNG IUS is often inaccessible due to financial barriers and supply chain challenges.

THE PROGRESS The ICA Foundation was established in 2003 to help overcome these obstacles by making the LNG IUS available at no cost in resource-poor settings. To date, the Foundation has provided over 67,000 LNG IUS and training materials to projects in 28 low- and middleincome countries. To become a project of the Foundation, eligible organizations must submit an application describing their plans for integrating the LNG IUS into their reproductive health service delivery activities. This local responsibility ensures that the donated LNG IUS are distributed in a culturally-appropriate and acceptable manner.

THE IMPACT Two of the ICA Foundation's most successful projects are highlighted here to illustrate the impact of this important work.
BRAZIL: Since becoming an ICA Foundation project in 2006, the Center for Research in Reproductive Health of Campinas (CEMICAMP) and the University of Campinas School of Medicine's Department of Obstetrics and Gynecology (UNICAMP) has provided an average of 271 women per month with free LNG IUS insertions at more than 20 sites throughout Brazil. It is the Foundation's largest project, having received nearly $21 \%$ of all LNG IUS donations made in the past decade (over 14,000 devices) and trained nearly 100 health professionals across Brazil on counseling and insertion/removal techniques. The project is led by Prof. Dr. Luis Bahamondes, an eminent $\mathrm{OB} / \mathrm{GYN}$ based in Campinas.
NIGERIA: With 35 sites across Nigeria, Rotary International has received 7,500 LNG IUS donations since becoming an ICA Foundation project in 2007. Local partners have developed and implemented health provider education and community outreach activities involving men and religious leaders in family planning promotion, and women served by project sites report very high acceptance of the LNG IUS. The project is led by Robert Zinser, Chief Executive Officer of the Rotarian Action Group for Population and Development and a long-standing champion for maternal health and family planning.

DONORS Bayer HealthCare Pharmaceuticals, Population Council 


\section{SCIENTIST AT THE POPULATION COUNCIL'S} CENTER FOR BIOMEDICAL RESEARCH (CBR)

\section{BARBARA EBERT}

\section{COUNCIL DONOR}

Tell us about the work you do.

I lead the preclinical virology group in the microbicides laboratory at CBR. We conduct research to identify compounds that might be active against HIV and other sexually transmitted pathogens such as genital herpes simplex virus (HSV-2) and human papillomavirus (HPV). After one or more compounds has been formulated as a product candidate (for example, as you read about on page 8 ) and before any human testing is done, we conduct rigorous studies on these microbicide and multipurpose prevention technology (MPT) candidates to ensure they are safe and effective. These preclinical studies are necessary in order to identify the most promising microbicide and MPT candidates to be further developed and tested in people.

Why did you choose to do this work at the Council?

The Population Council has a rich history of improving the lives and expectations of millions of people. Our HIV prevention program follows the same philosophy of empowering the world's most vulnerable by working to make user-controlled microbicides and MPTs a reality.

What led you to enter the field of biomedical research?

My passion for virology started 20 years ago when I began studying microbiology. This was back in the 1990s, when people began paying more attention to the global impact of HIV and AIDS. After I received my bachelors degree in microbiology at the University of Havana, I stayed to teach virology and genetic engineering while conducting research on indigenous plants and their potential for antiviral activity. Soon after I arrived in the US from Cuba, the Council introduced me to the new idea of HIV prevention through microbicides, and I decided to use my expertise in virology to serve the microbicide research community. Today my goal is to help develop potential MPTs that protect women and men not only from HIV but also other sexually transmitted infections (STIs) and unintended pregnancy.

What has been most rewarding for you in your career?

I have enjoyed helping build a team with the unique expertise to test potential products against three major, noncurable viral STIs. I am lucky to work with colleagues who understand the importance of teamwork and are passionate about the work we do. I also teach biology and microbiology at Hostos Community College in the Bronx-a gratifying experience for me, especially when some of my students, many of whom are minorities, decide to pursue a career in biology. I hope that by teaching at Hostos, I can make a modest contribution to raise the profile of minorities in the sciences.
I give to the Population Council because of the long association my late husband, Dr. Robert Ebert, had with the organization-30 years as a board member, 10 years as chair. He considered the Population Council one of the most important and effective organizations he had the privilege of serving.

Bob spent his career in academic medicine-as bench scientist, clinician, and medical school dean. He worked on new drugs to treat tuberculosis and was continually challenged to translate his research to the bedside as quickly as possible. He saw how new drugs improved people's lives. He cared deeply about public health issues, including efficient and cost-effective delivery of medical care to needy populations, prevention of communicable diseases, and family planning. Becoming a trustee of the Population Council extended his interest in public health to the global level. He became even more committed to developing new products and initiatives to improve the reproductive health of women in developing nations.

It was my privilege and good fortune to accompany him on some board meetings in Africa. One took us to Senegal and Mali, where we visited clinics for and managed by women. These women stressed the importance of good health, prenatal care, and family planning. When
WHY I GIVE TO THE POPULATION COUNCIL

we arrived at one clinic, the clients having been told that Population Council Trustees were coming to visit, were waiting for us all dressed up. They passed their babies to us to hold and coo over (in fractured French for most of us). They used theater to illustrate the important health issues they faced; we saw two skits in which women impressed upon their husbands the importance of family planning. They played these parts with a good deal of humor-including an irate mother who browbeat her son for getting his wife pregnant again-and were very effective in putting their point across.

While I make modest gifts to other family planning organizations, I am particularly impressed with the broad scope of the Council's influence throughout the world. Family planning is obviously one, but the work of the Center for Biomedical Research in developing safe, innovative, and affordable contraceptives has made a huge impact in this area. Addressing other issues such as HIV prevention, education and safe spaces for girls, and poverty alleviation makes the Population Council stand out as a leader. 


\section{WITH YOUR HELP, WE CAN}

CONTINUE TO PROVIDE

PEOPLE WITH NEW PRODUCTS

TO SAFEGUARD THEIR

REPRODUCTIVE HEALTH AND WELLBEING.

\section{Support the}

Population Council:

popcouncil.org/supporting

Sign up for the Council's

e-mail list:

popcouncil.org

(Click "Subscribe" on the homepage)

-

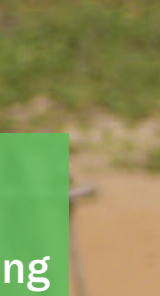

t.

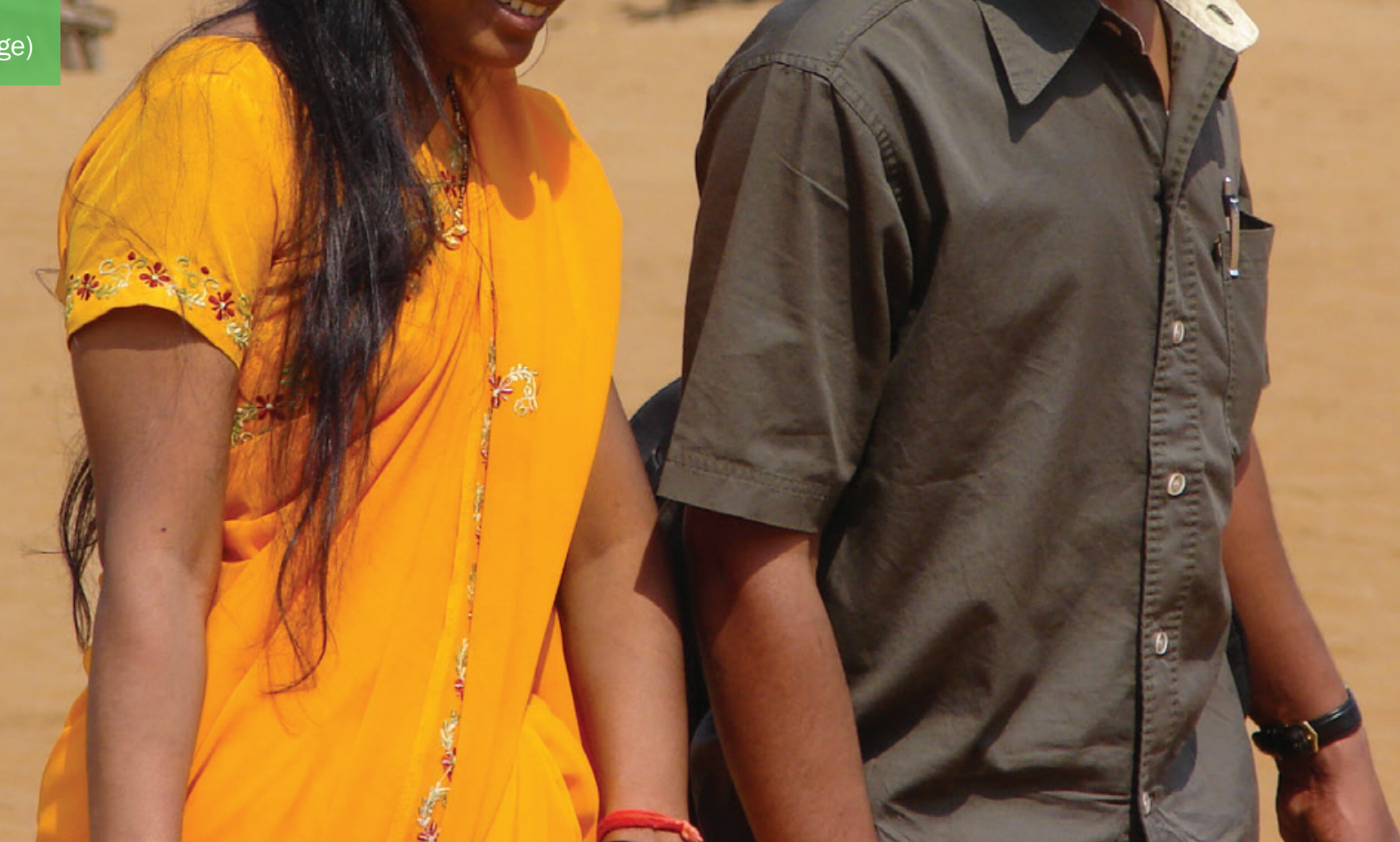


